Objective: To establish the obesity incidence according to BMI (body mass index) in 1st Department of Gynecology Iasi and to correlate the grade of obesity with prognostic factors. We also looked at the challenges of treating EC caused by obesity.

Methodology It was a prospective study on 110 pacients with surgical treatment for EC from the $1^{\text {st }}$ Clinic of Gynecology Iasi between January 2014-June 2021. We evaluated the BMI of the patients defined by WHO. For 15 women we made correlation between others parameters for assessing obesity and aggressiveness of EC.

Result(s)* The mean age of the patients was 60.15 years (limits $36-87$ years). $83.33 \%$ of the cases were diagnosed with stage I cancer. 54 women were obese. Most of them associated hypertension with obesity-36, 27 cases had diabetes with obesity and only 25 women presented the classic triad hypertension-diabetes-obesity. We didn't find statistic correlation between obesity rate and disease stage $(p=0.427)$, tumor grading $(\mathrm{p}=0.690)$ or vascular invasion $(\mathrm{p}=0.84) .5$ patients presented wound infection, 3 had dehiscent scar.

Conclusion* Obesity is involved in disease pathogeny but cancer aggressiveness is not correlated with the grade of it. The association between obesity and hypertension determines a more advanced stage of disease and increases the grading. The classical risk triad was not statistically influenced the stage $\mathrm{p}=0.580$ and grading $\mathrm{p}=0.098$. Weight loss after surgery is a priority for decreasing the rate of recurrence, but in our country few patients understand the importance of this goal.

\section{ENDOMETRIAL CANCER IN A DEVELOPING COUNTRY; EMERGING TREND}

${ }^{1} \mathrm{M}$ Umemmuo*, 'E Oladunni, ${ }^{2} \mathrm{~F}$ Igbinoba. 'National Hospital Abuja, Department of Obstetrics and Gynaecology, Abuja, Nigeria; ${ }^{2}$ National Hospital Abuja, Department of oncology, Abuja, Nigeria

\subsection{6/ijgc-2021-ESG0.231}

Introduction/Background* Cancer of the uterine corpus is the most common pelvic gynecologic malignancy in developed countries and has been reported to be on the increase in developed countries. However, there is a paucity of data on the trend of endometrial cancer in developing countries.

Methodology A 10-year review of endometrial malignancies (2011-2020) at a tertiary institution in Nigeria. Data on endometrial cancer were generated using a cancer registry (ICD-10 CanReg5 software). There were 93 endometrial malignancies during the period and data was analyzed using SPSS version 22

Result(s)* A total of $93(100 \%)$ were analyzed. Most of the patients had tertiary education $51 \quad(56.7 \%$ 54.8\%). The peak age range was 60-69years (34\%) followed by 50-59years (26\%). However, $5(5.4 \%)$ cases recorded were below the age of 40years. Approximately $65(69.9 \%)$ cases of endometrial carcinomas were endometrioid adenocarcinomas. Other histologic subtypes include; adenosquamous 11 (11.8\%), Papillary $8(8.6 \%)$ sarcomas $7(7.5 \%)$, and 1 (1.1\%) for clear cell type, and mixed Mullerian tumour respectively. The histological forms of the five $(5.4 \%)$ recorded in under 40years patients were endometrioid adenocarcinoma $3(60 \%)$ and adenosquamous $2(40 \%)$. There was a sustained rise in the prevalence of endometrial cancer from 4 (4.3\%) in 2016 to 21 (22.6\%) in 2018 with a slight decline to 18 (19.4\%) in 2019.
Abstract 1134 Table 1 showing the number of cases for different age groups over the 10 years' period

\begin{tabular}{llllllll}
\hline $\begin{array}{l}\text { YEAR/AGE } \\
\text { GROUP }\end{array}$ & $30-$ & $40-$ & $50-$ & $60-$ & $\begin{array}{l}70- \\
79\end{array}$ & $\begin{array}{l}80 \\
+\end{array}$ \\
\hline 2011 & 39 & 49 & 59 & 69 & 79 & \\
2012 & 0 & 0 & 2 & 2 & 0 & 0 & 4 \\
2013 & 0 & 1 & 3 & 1 & 1 & 2 & 8 \\
2014 & 0 & 1 & 1 & 3 & 0 & 2 & 7 \\
2015 & 0 & 2 & 0 & 2 & 1 & 0 & 5 \\
2016 & 0 & 2 & 4 & 1 & 1 & 0 & 8 \\
2017 & 0 & 1 & 1 & 1 & 1 & 0 & 4 \\
2018 & 2 & 0 & 4 & 3 & 1 & 1 & 11 \\
2019 & 3 & 2 & 4 & 10 & 2 & 0 & 21 \\
2020 & 0 & 2 & 6 & 7 & 2 & 1 & 18 \\
TOTAL & 0 & 2 & 1 & 4 & 0 & 0 & 7 \\
\hline
\end{tabular}

\section{TREND OF ENDOMETRIAL CA FROM 2011-2020}

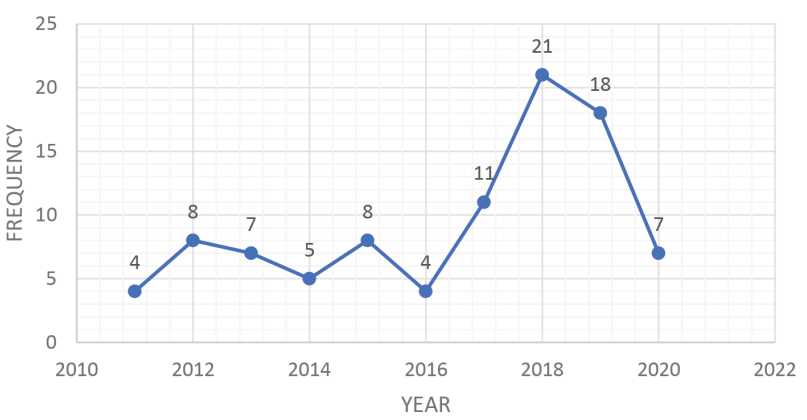

Abstract 1134 Figure 1 Trend of endometrial CA from 2011-2020

However, in 2020 a sharp decline was recorded. The occurrence of endometrial cancer in the younger age group (below 40 years) was recorded during the period of the sudden rise in the prevalence of endometrial cancer.

Conclusion* Given the increasing prevalence of endometrial cancer in our setting, there is a need for lifestyle modifications and increase awareness of endometrial cancer. More research efforts and aids are needed in other to curb the increasing trend of this problem in developing countries.

\section{A PILOT STUDY FOR THE VALIDATION OF SENTINEL LYMPH NODE BIOPSY WITH FLUORESCENCE METHOD IN EARLY ENDOMETRIAL CANCER}

J García Villayzan*, M Albi Gonzalez, J Utrilla -Layna. Madrid, Madrid, Spain

\subsection{6/ijgc-2021-ESG0.232}

Introduction/Background* Sentinel Lymph Node Biopsy is a technique developed to predict lymphatic involvement in patients with early endometrial cancer, decreasing the morbimortality associated with routine systematic lymphadenectomy and improving quality of life.

Methodology

Main Objective To determine the detection rate and negative predictive value of the Sentinel Lymph Node Biopsy by Immunofluorescence in patients with early endometrial cancer. Method A descriptive observational study in patients with early endometrial cancer (FIGO stage I-II) for all histological 